\title{
STOCK MARKET VOLATILITY MEASURE USING NON- TRADITIONAL TOOL CASE OF GERMANY
}

\author{
Naeem AHMED ${ }^{1}$, Mudassira SARFRAZ ${ }^{1,2}$ \\ ${ }^{1}$ COMSATS University, Islamabad, Pakistan \\ ${ }^{2}$ University of Warsaw, Warsaw, Poland \\ Corresponding author's e-mail: naeem_ahmed@comsats.edu.pk
}

\begin{abstract}
This study examines the stock market volatility of German benchmark stock index DAX 30 using logarithmic extreme day return. German stock markets have been analyzed extensively in literature. We look into volatility issue from the standpoint of extreme-day changes. Our analysis indicates the non-normality of German stock market and higher probability of negative trading days. We measure the occurrences of extreme-day returns and their significance in measuring annual volatility. Our time series analysis indicates that the occurrences of extreme-days show a cyclical trend over the sample time period. Our comparison of negative and positive extreme-days indicates that negative extreme-days overweigh the positive extreme days. Standard deviation, as measure of volatility used traditionally, gives altered ranks of annual volatility to a considerable extent as compared to extreme-day returns. Lastly, existence of extreme day returns can be explained by past period occurrences, which show predictability.
\end{abstract}

Keywords: Extreme-day return, non-normality, standard deviation, volatility, volatility ranking.

JEL Classification: G10

\section{INTRODUCTION}

Stock market volatility is a well thought out topic and has vital importance for investor's decision-making, thus having considerable influence on investor's behaviour in the market, as it gives insights about risk and return trade-off. Several methods are used in practice for measuring asset return volatility, but gradually standard deviation had been mostly used traditionally. Standard deviation/Variance of returns has been extensively used as a proxy for risk in financial returns (Campbell, 2004). Standard deviation is considered useful, but at the same time not reliable as a measure of risk. Longin (1996) while analyzing risk and extreme values of the US stock prices from 1885 to 1990 argued that tail analysis is superior to standard deviation. Standard deviation gives misleading results in the daily stock returns due to absence of normal distribution and non-stationary trend with positive and negative autocorrelation overtime (Jones, Walker \& Wilson, 2004). Switzer, Wang and Lee (2017) document the extreme-day return measure better than standard deviation risk measure for small investor's behaviour in US and Canada. On the same lines, Wander and Vari (2003) put forward that standard deviation contains some flaws as a risk measure but it gives some useful insights. Nelken 
(1997), while describing the stock prices series of Motorola, also rejected standard deviation as a reliable measure of volatility, since standard deviation is deviation from mean, which does not remain constant throughout the series. Mathematically variance calculation overlooks the extreme variations, practically one extreme change (positive or negative) in stock price has long lasting impact on returns. Several academicians generally quote stock market crash in 1987 as an example. For investors a negative extreme-day change (downside risk) is more alarming, mainly risk mitigation strategies are focused on losses. After every market crisis increases the demand for strategies that deal with significant negative returns. Investors look at losses more determinedly than gains, observing negative extreme changes more closely (Burnie \& De Ridder, 2010). Thus, standard deviation does not give an ample answer to the prime concern (loss) of investors. These limitations put question mark on standard deviation as a reliable measure of volatility (risk).

Eventually extreme value analysis is visible in literature. Pactwa (2001) empirically examined the extreme price movements of S\&P 500 index (Jondeau \& Rockinger, 2003) and analyzed the extreme return tails for 20 mature and emerging markets of the world in investor perspective. Similarly, Assaf (2009) used extreme observations and portrayed it as better risk measure and management approach analyzing the equity markets of Middle East and North Africa (MENA) region. Jones, Walker and Wilson (2004), as well as Burnie and De Ridder (2010) have utilized extreme day returns as risk measure to see investor behaviour.

In this paper, authors measure and analyze the volatility in German stock market through extreme-day return proposed by Jones, Walker and Wilson (2004) and compare with volatility calculated by standard deviation. This measure is not high flying in literature as standard deviation. The authors study how extreme day returns analysis interprets the annual stock market returns volatility in different ways. Further trend analysis of extreme day returns occurrences and comparison of positive and negative extreme day returns annually in particular is carried out to highlight downside risk. Lastly, using this measure we analyze to what extent the risk can be predicted by past annual risk. Rest of the paper is organized as follows: Section 2 contains literature on extreme value theory; Section 3 discusses methodology and chosen data; in Section 4 the authors present the results; and in Section 5 the conclusion is made.

\section{VOLATILITY MEASURE BASED ON EXTREME VALUE THEORY}

The literature considers several ways to measure stock market volatility. In the past unconventional characterizations of risk have been recognized, which shows that investors do not use traditional definitions of risk (Benartzi \& Thaler, 1995). Veld and Veld-Merkoulova (2008) document that most investors indirectly use more than one risk tool in addition to dispersion measure variance.

The non-normality of stock return series is well known, basic descriptive statistics about normality like skewness and kurtosis reveal the significance of extreme returns in return distribution valuation. Extensive literature documents departure from normality of stock return distributions. Stock return distributions have negative skewness and excess kurtosis (Harvey \& Siddique, 1999). Excess 
kurtosis indicates the presence of extreme values in return distribution above the normality. Particularly excess kurtosis means that market gives high probability to extreme returns (Dubauskas \& Teresienè, 2015). Over the last decades in financial literature, focus has been on extreme-day returns and extreme value theory. Extreme-day returns are generally occurring rarely, they are associated with large extreme values and difficult to predict. Extreme values have considerable valuation impact despite far departure from normality. Bogle (2008) and Estrada (2008) have characterized and named fat tails / extreme returns as 'Black Swan'.

An alternative measure of volatility, which has been in use by researchers taking into consideration, is the frequency of extreme-day returns (positive and negative) proposed by Jones, Walker and Wilson (2004). Volatility using this measure is simple and independent of statistical distribution, measuring volatility using extreme-day return can be categorized as an alternative measure of risk (Jones, Walker \& Wilson, 2004). This measure is comparatively sound as compared to standard deviation. The prime benefit is classification of positive and negative extreme day returns. That is more explanatory and explicit about the risk.

\section{DATA \& METHODOLOGY}

\subsection{Data}

We are using secondary data in our study - the closing prices of German major stock index DAX 30. DAX (Deutscher Aktienindex) is a blue-chip stock market index consisting of the 30 major German companies trading on the Frankfurt Stock Exchange. The daily closing prices change is utilized throughout our study, excluding cash dividends. The time period covered in this study is from January 1991 to December 2015, consisting of 6332 trading days. Germany is considered a leading economy in European Union. During the sample period, there have been several economically significant cycles in Europe.

\subsection{Methodology}

It is well known that arithmetic mean of returns is non-symmetric, whereas geometric mean is symmetric as it considers the effect of continuous compounding. Therefore, it is in line with standard method for calculating the share price volatility in short run. We also use the standard measure daily prices / rate of change of indexes continuously compounded as follows:

$$
\mathrm{R}=100 * \ln \left(\frac{P_{\tau}}{P_{\tau-1}}\right),
$$

where

$R$ is continuous compounding return, $P_{\tau}$ is current day price and $P_{\tau-1}$ is the price of previous trading day. 


\subsection{Definition of extreme day returns}

There is no wide-ranging definition of extreme day in literature so far. Notably, Jones, Walker and Wilson (2004) defined an extreme day as a trading day with an absolute daily logarithmic percentage change greater than or equal to $1.5 \%$, using the sample from USA. Similar definition has been proposed by De Ridder and Djehiche (2007) using the sample of Sweden. On the other hand, Pactwa (2001) has used $2 \%, 3 \%$, and $4 \%$ absolute change as an extreme day return. It is evident from past studies that the definition of extreme days varies from lower end $1.5 \%$ to upper end $4 \%$ absolute daily logarithmic percentage change.

Therefore, in this study, like in earlier few studies, an extreme day is regarded as a trading day with an absolute daily logarithmic percentage change greater than or equal to $1.5 \%$. If absolute percentage change is $+1.5 \%$ or above increase, that will be regarded as positive extreme day, whereas a decrease of $1.5 \%$ or lower will be considered as negative extreme day. Positive and negative extreme day returns are decomposed as follows.

Upper tail: Absolute logarithmic percentage change on market returns $\geq+1.5 \%$ Lower tail: Absolute logarithmic percentage change on market returns $\leq-1.5 \%$

\section{RESULTS}

Table 1 provides the descriptive statistics for our sample over the period 19912015. A few important points can be noted here with respect to our observations. Overall, the mean (median) logarithmic daily percentage change is $0.033 \%$ $(0.079 \%)$. Negative skewness means that the distribution has a longer left tail; it also infers recurrent small gains and a few extreme gains about investment returns. That means higher probability of decrease than increase in asset pricing. The same has been reinforced by excess kurtosis above normality, 4.6 exceeds the kurtosis value 3 for normal distribution categorizing return distribution leptokurtic. JarqueBera value tells the same story. Logarithmic daily return distribution has fatter tails and less chances of extreme return as compared to normal. Thus, our log return statistics in Table 1 openly discard the hypothesis of normal distribution.

Table 1 illustrates the summary statistics and the distribution of daily logarithmic percentage changes on the Frankfurt Stock Exchange during 1991 to 2016. An extreme day return is defined as a daily logarithmic return less than or equal to $-1.5 \%$ or equal to or more than $1.5 \%$.

The authors discovered the extent of extreme day returns over our sample period by using simple time-series analysis of our data. As can be seen from Fig. 1, the data gives findings that the frequency of extreme days has a strong cyclical trend. The frequency of extreme days from 1991 till 1996 during these five calendar years show that there is a mild cycle of up and down; year 1996 has been found containing the least percentage of extreme days- 5.6\%. Onward, there has been almost sharp increase in the magnitude of extreme day returns, except in 1999. The highest percentage in the calendar year 2002, where $57 \%$ extreme day returns are reported, possible explanation for this is bursting of the technology bubble in early 2000 . 
Table 1. Summary Statistics of Daily Returns on the German Stock Market Between 1991 and 2016

\begin{tabular}{|l|r|}
\hline \multicolumn{1}{|c|}{ Statistics value } & Value \\
\hline Mean & 0.032569 \\
\hline Standard Error & 0.017997 \\
\hline Median & 0.079079 \\
\hline Mode & 0 \\
\hline Standard Deviation & 1.432080 \\
\hline Sample Variance & 2.050853 \\
\hline Kurtosis & 4.597842 \\
\hline Jarqque-Bera & 5578.484000 \\
\hline Skewness & -0.107130 \\
\hline Range & 20.668390 \\
\hline Minimum & -9.870920 \\
\hline Maximum & 10.797470 \\
\hline Sum & 206.229500 \\
\hline Count & 6332 \\
\hline
\end{tabular}

There have been two major international crisis, namely, global financial crises 2007-8 and euro zone crisis, which started at the end of 2009. As reported in Fig. 1, occurrence of extreme day returns surprisingly do not show turmoil during these two crises, high volatility jumps are not visible as herding was reported in literature on other global stock markets.

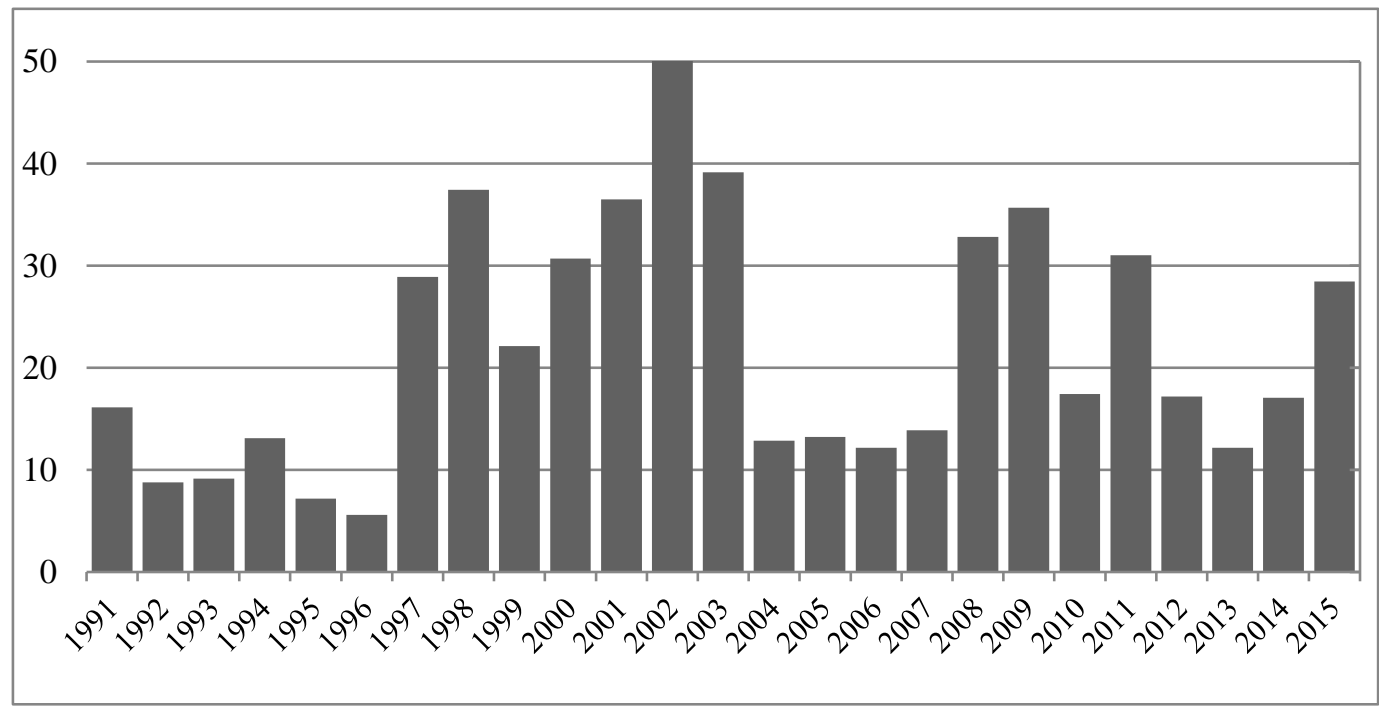

Fig. 1. The development of extreme day returns on the Frankfurt Stock Exchange from 1991 to 2015.

The authors highlight downside risk, for which we further narrow down the occurrence of extreme days by comparing annual upper and lower tails in Fig. 2. For overall sample period out of 25 years, 10 years lower tails are heavier than upper tails, similarly 11 years have heavier upper tails while 4 years upper and 
lower tails are of equal weight. The heaviest lower tail reported is in year 2005, where $76 \%$ of total annual trading days turned out to be in negative extreme- day return, year 1993 reported $65 \%$ of negative extreme days. While $61 \%$ of positive extreme day returns occurrences was reported in year 2006 with the heaviest upper tail during the sample period. Interestingly, the heaviest lower and upper tails occurred simultaneously in consecutive years 2005 and 2006, respectively. Generally, lower tails are of greater magnitude as compared to upper tails. That is revealing occurrences of negative extreme days at larger scale, as indicated by skewness and kurtosis measures. Thus, there is more downside risk.

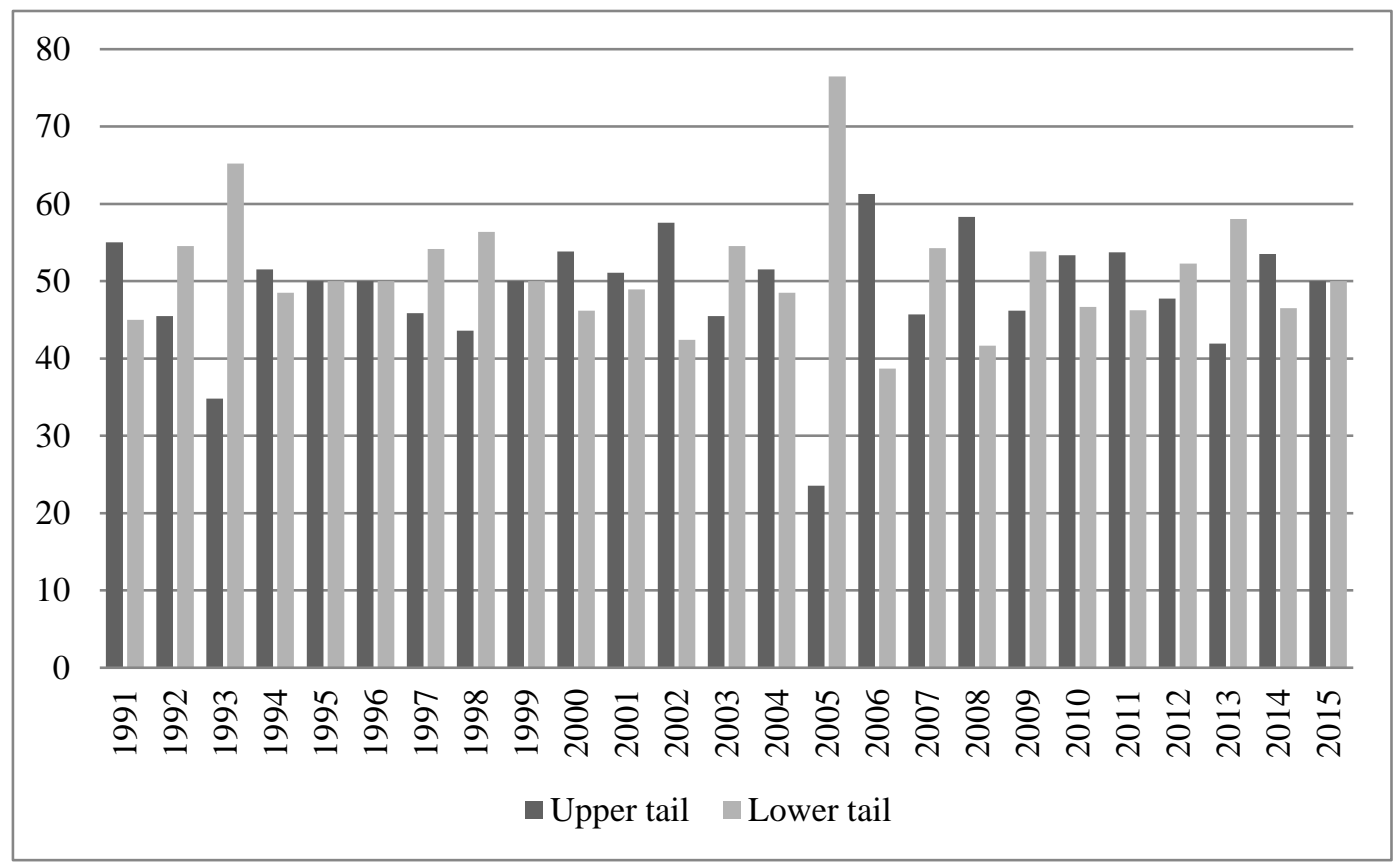

Fig. 2. Comparison of upper and lower tails on the Frankfurt Stock Exchange from 1991 to 2015.

Figure 2 shows the comparison of upper and lower tails on the Frankfurt Stock Exchange from 1991 to 2015. An upper tail is composed of annual percentage of total extreme days with absolute logarithmic percentage change on market returns $\geq+1.5 \%$, while the lower tail is composed of an annual percentage of total extreme days with absolute logarithmic percentage change on market returns $\leq-1.5 \%$.

Next, the authors rank the German stock market volatility by standard deviation and percentage of extreme days. Table 2 gives the summary of rankings of volatility for logarithmic percentage returns. We place 25 years of volatility as measured by standard deviation on the left side of the table and the ranking using percentage of extreme days on the right side. An asterisk is provided to show years with same ranking by both volatility measures. The largest value of standard deviation is in 2002 at 2.48, next three positions occupy years 2008, 2003 and 2003. According to this volatility measure, least volatile years are 1995, 1996 and 2005 with smallest standard deviation 0.76 . 
Table 2. Rank of Volatility as Measured by the Standard Deviation and by the Percentage of Extreme Days for 25 years

\begin{tabular}{|c|c|c|c|c|c|}
\hline \multicolumn{3}{|c|}{ Standard Deviation } & \multicolumn{3}{|c|}{ Percentage of Extreme-Days } \\
\hline Rank & Year & StdDev & Years & Percent & Rank \\
\hline 1 & $* 2002$ & 2.48 & $* 2002$ & 52.17 & 1 \\
\hline 2 & 2008 & 2.36 & 2003 & 39.13 & 2 \\
\hline 3 & 2003 & 2.05 & 1998 & 37.45 & 3 \\
\hline 4 & 1998 & 1.82 & 2001 & 36.51 & 4 \\
\hline 5 & 2001 & 1.80 & 2009 & 35.69 & 5 \\
\hline 6 & 2009 & 1.79 & 2008 & 32.81 & 6 \\
\hline 7 & $* 2011$ & 1.76 & $* 2011$ & 31.01 & 7 \\
\hline 8 & $* 2000$ & 1.51 & $* 2000$ & 30.71 & 8 \\
\hline 9 & *1997 & 1.49 & $* 1997$ & 28.92 & 9 \\
\hline 10 & $* 2015$ & 1.48 & $* 2015$ & 28.46 & 10 \\
\hline 11 & *1999 & 1.36 & $* 1999$ & 22.13 & 11 \\
\hline 12 & 2012 & 1.22 & 2010 & 17.44 & 12 \\
\hline 13 & 2010 & 1.14 & 2012 & 17.19 & 13 \\
\hline 14 & 1991 & 1.14 & 2014 & 17.06 & 14 \\
\hline 15 & 1994 & 1.05 & 1991 & 16.13 & 15 \\
\hline 16 & 2014 & 1.05 & 2007 & 13.89 & 16 \\
\hline 17 & 2004 & 0.99 & 2005 & 13.23 & 17 \\
\hline 18 & 2007 & 0.98 & 1994 & 13.10 & 18 \\
\hline 19 & 2006 & 0.97 & 2004 & 12.84 & 19 \\
\hline 20 & 2013 & 0.92 & 2006 & 12.16 & 20 \\
\hline 21 & 1992 & 0.90 & 2013 & 12.16 & 21 \\
\hline 22 & *1993 & 0.88 & *1993 & 9.13 & 22 \\
\hline 23 & 1995 & 0.83 & 1992 & 8.76 & 23 \\
\hline 24 & 1996 & 0.82 & 1995 & 7.17 & 24 \\
\hline 25 & 2005 & 0.76 & 1996 & 5.60 & 25 \\
\hline
\end{tabular}

The asterisk (*) denotes years that are similar by both risk measures

As Table 2 shows, the percentage of extreme days rank year 2002 as first, the same as by the volatility measure standard deviation. In 2002, there were 76 positive and 56 negative extreme days out of 253 trading days, or $52.17 \%$ of total time during the year. The other years having the same rank order are 2011, 2000, 1997 , 2015, 1999 and 1993.

Next, the authors measure the predictableness of frequency of extreme-days of past to predict the future extreme dates. The authors employ simple OLS-regression model, where dependent variable is annual frequency of extreme-days, where frequency of extreme-days is the ratio of number of total extreme-days to total number of trading days in year $t$ and independent variable is the same but of previous year $(t-1)$ stated in Formula 2.

Frequency extday, $t=a+b($ Frequency extday, $t-1)+e$, 
To run regression we had annual frequencies for 25 years, after adjusting the left column with 24 observations. We checked autocorrelation issue by applying Durbin-Watson statistics, reported value of statistics is 1.699863. A rule of thumb is that test statistic values in the range of 1.5 to 2.5 are relatively normal. Values outward of this array could be awkward. Field (2009) proposes that values under 1 or more than 3 are a surely cause for concern.

Table 3 shows the OLS regression results for our overall sample period where the dependent variable is the annual frequency of extreme days in year $t$ and the independent variable is also annual frequency of extreme days but of the previous year, year $t-1$, model (1).

Table 3. OLS-model estimates of annual extreme day return frequencies for overall sample period 1991-2015.

\begin{tabular}{|c|c|c|c|c|c|}
\hline \multicolumn{7}{|c|}{ Frequency extday, $t=a+b($ Frequency extday, $t-1)+e$} \\
\hline Period & Obs. & $\begin{array}{c}\text { Intercept } \\
\text { (a) }\end{array}$ & $\begin{array}{c}\text { Estimated Slope Coefficient } \\
\text { (b) }\end{array}$ & R2 & F-value \\
\hline $1991-2015$ & 24 & 0.1 & $0.52 * * *$ & 0.27 & 8.33 \\
\hline & & $(2.19)$ & $(2.88)$ & & \\
\hline
\end{tabular}

The t-statistics are within parentheses and $* * *$ denote significant at the $1 \%$ significance level.

In Table 3, the authors report OLS-model estimates of annual extreme day return frequencies for overall sample period 1991-2015. As indicated by regression results, we obtain statistically significant estimates for overall time 24-year period at $1 \%$ significance level. The estimated coefficient of extreme day return frequency is positive, indicating positive correlation with past year. Positive coefficient estimate 0.52 statistically significant at $1 \%$ level conditions that frequency of extreme day returns are explained less than unity by preceding year frequencies. Thus, frequency of past year does predict the frequency of extreme days in future year. $\mathrm{R}^{2}$ shows that $27.5 \%$ of frequency of extreme day returns is explained by the prior year frequency of extreme days over the whole sample period. The authors' estimate of regression standard error and sum squared residuals are 0.108951 and 0.261146 , respectively.

\section{CONCLUSION}

In this paper the authors examine the stock market volatility in Germany based on extreme-day returns. First, the authors examine the frequency of extreme day return defined as a trading day when the absolute logarithmic percentage change on the market return is equal to or greater than $1.5 \%$. For a sample of 6332 daily observations over the time period 1991-2015, we find the cyclical trend of annual frequencies based on extreme day returns; surprisingly, occurrences of extreme day returns are not high during the global financial crisis and 'euro crisis'. Over the sample period we find heavier annual lower tails (loss), indicating that magnitude of negative extreme day occurrence is greater than of positive extreme days. This clearly indicates that the downside risk is not consistent over 25 years. Rankings of annual volatility based on annual standard deviation and annual frequency of 
extreme day returns are the same for the highest volatile year 2002, along with other 6 years. This clearly gives two perspectives of risk from the same time period. The authors' regression model applied on annual frequencies of extreme-days for 24 years states that volatility is correlated with past year volatility. Thus, extreme day returns can be predicted based on prior years' occurrences.

\section{REFERENCES}

Assaf, A. (2009). Extreme Observations and Risk Assessment in the Equity Markets of MENA Region: Tail measures and Value-at-Risk. International Review of Financial Analysis, 18(3), 109-116. https://doi.org/10.1016/j.irfa.2009.03.007

Benartzi, S. \& Thaler, R. (1995). Myopic Loss Aversion and the Equity Premium Puzzle. Quarterly Journal of Economics, 110, 73-92.

Bogle, J. C. (2008). Black Monday and Black Swans. Financial Analysts Journal, 64, 30-40.

Burnie, D., \& De Ridder, A. (2010). Far tail or extreme day returns, mutual fund cash flows and investment behaviour. Applied Financial Economics, 20 (16), 1241-1256.

Campbell, R. (2004). Harvey Duke University, Durham, NC 27708, USA.

Dubauskas, G., \& Teresienė, D. (2015). Autoregressive Conditional Skewness, Kurtosis and Jarque-bera in Lithuanian Stock Market Measurement. Engineering Economics, 45, 25-30. https://doi.org/10.5755/j01.ee.45.5.11329

Estrada, J. (2008). Investing in Emerging Markets: A Black Swan Perspective. Retrieved from http://ssrn.com/abstract=1308082.

Field, A. P. (2009). Discovering statistics using SPSS: and Sex and Drugs and Rock 'n' Roll (3rd edition). London: Sage.

Harvey, C. R., \& Siddique, A. (1999). Autoregressive Conditional Skewness. The Journal of Financial and Quantitative Analysis, 34, 465-487. https://doi.org/10.2307/2676230

Jondeau, E. \& Rockinger, M. (2003). Testing for differences in the tails of stock-market returns. Journal of Empirical Finance, 10 (5), 559-581. https://doi.org/10.1016/S0927-5398(03)00005-7

Jones, C. P., Walker M. D. \& Wilson J. W. (2004). Analyzing Stock Market Volatility Using Extreme-Day Measures. Journal of Financial Research, 27 (4), 585-601.

Longin, F. M. (1996). The asymptotic distribution of extreme stock returns, Journal of Business, 69, 383-408.

Nelken, I. (1997). Volatility in the Capital Markets: State Of-The-Art Techniques for Modelling, Managing and Trading Volatility, illustrated March edn, Eric Dobby Publishing.

Pactwa, T. E. (2001). Using Extreme Value Theory to Value Stock Market Returns. ProQuest ETD Collection for FIU, 1-129.

De Ridder, A., \& Djehiche, B. (2007). Extreme Day Returns on Stocks: Evidence from Sweden.

Switzer, L. N., Wang, J. \& Lee, S. (2017). Extreme Risk and Small Investor Behavior in Developed Markets. Journal of Asset Management, 1-19. https://doi.org/10.1057/s41260-017-0047-6

Veld, C., \& Veld-Merkoulova, Y. V. (2008). The Risk Perceptions of Individual Investors. Journal of Economic Psychology, 29(2), 226-252.

Wander, B. H. \& Vari R. D. (2003). The Limitations of Standard Deviation as a Measure of Bond Portfolio Risk. The Journal of Wealth Management 6, 3(1), 35-38.

\section{AUTHORS' SHORT BIOGRAPHIES}

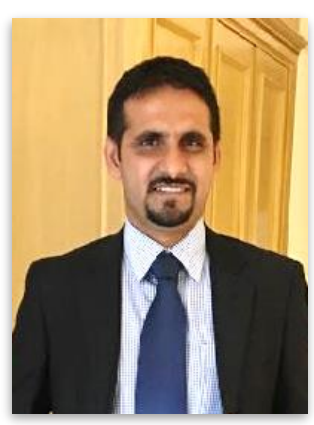

Naeem Ahmed received the Master degree in International Management in 2010 from Gotland University (now Uppsala University), Sweden. His Master Thesis was on international stock market volatility comparison of developed and emerging capital markets of the world. He is currently an Assistant Professor in COMSATS Institute of Information Technology Islamabad, Pakistan. He has been teaching the courses on Finance and Economics to undergraduate students in COMSATS University, Islamabad, Pakistan. His research area covers the topics in International Stock Market and portfolio diversification environment, and corporate governance.

E-mail: naeem_ahmed@comsats.edu.pk 


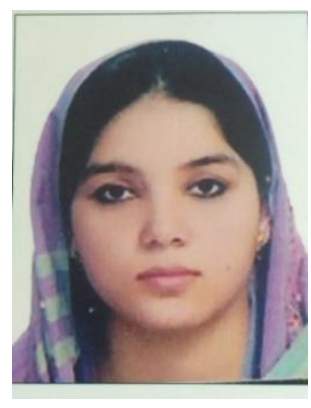

Mudassira Sarfraz received the Master degree in International and Development Economics from the Australian National University, Canberra, Australia in 2009. Presently, she is a Ph.D. student at the Faculty of Management, University of Warsaw, Poland. She is also an Assistant Professor at COMSATS University, Islamabad, Pakistan. She has been teaching Economics to undergraduate students at COMSATS University, Islamabad, Pakistan. Her research area is development economics and social capital.

E-mail: mudassira_sarfraz@comsats.edu.pk

ORCID iD: https://orcid.org/0000-0002-8295-8591 